Research Article

\title{
Separation and Enrichment of Omega 3, 6, and 9 Fatty Acids from the By-Products of Vietnamese Basa Fish Processing using Deep Eutectic Solvent
}

\author{
Thanh Xuan Le Thi $\mathbb{D}^{1,2}$ Hoai Lam Tran ${ }^{1 D},{ }^{3}$ Thanh Son $\mathrm{Cu}^{4}{ }^{4}$ and Son Lam Ho ${ }^{4}$ \\ ${ }^{1}$ Dong Thap University, Dong Thap, Vietnam \\ ${ }^{2}$ Graduate University of Sciences and Technology (GUST)-Vietnam Academy of Science and Technology (VAST), Vietnam \\ ${ }^{3}$ Department of Chemical Technology, Ho Chi Minh City University of Food Industry, Ho Chi Minh, Vietnam \\ ${ }^{4}$ Institute of Applied Materials Science (IAMS) - VAST, Vietnam \\ Correspondence should be addressed to Thanh Xuan Le Thi; lttxuan@dthu.edu.vn
}

Received 11 June 2018; Revised 9 October 2018; Accepted 25 October 2018; Published 2 December 2018

Guest Editor: Photis Papademas

Copyright (c) 2018 Thanh Xuan Le Thi et al. This is an open access article distributed under the Creative Commons Attribution License, which permits unrestricted use, distribution, and reproduction in any medium, provided the original work is properly cited.

\begin{abstract}
Omega 3, 6, and 9 fatty acids were separated and enriched successfully from the by-products of Vietnamese Basa fish processing by the deep eutectic solvent. The total amounts of omega fatty acids were about $57 \%$ in the raw material, and they were amounted to $91 \%$ after the first separation by DES. The optimal mass ratio is $20 \mathrm{~g}$ methyl ester with $200 \mathrm{~g}$ methanol and $15-20 \mathrm{~g}$ DES. Moreover, the ionic liquid-DES was successfully synthesized with the molar ratio of choline chloride/urea of $1: 1$ and $2: 1$. The characteristics of DES were determined and demonstrated by FTIR, TGA, DSC, ${ }^{1} \mathrm{H}-\mathrm{NMR}$, and ${ }^{13} \mathrm{C}-\mathrm{NMR}$ analysis methods.
\end{abstract}

\section{Introduction}

The scientific name of Basa fish is Pangasius bocourti, a catfish in the family Pangasiidae of high economic value, raised in many countries around the world. This species is native to the Mekong Delta in Vietnam and to the Chao Phraya River basin in Thailand [1]. This fish is an important food in the international market. In the Mekong Delta, catfish provide for essential demands over the country, and they are exported to other countries. It is promoting the development of Vietnamese fisheries industry. Average annual production of Vietnamese Basa-catfish from 2013 to 2017 is from 1.1 to 1.2 million tons. However, the main part of exporting fish is fillet meat and the other parts such as head, bone, fat, and skin (total $\sim 60-65 \%$ ) are still not fully utilized. The by-products of Basa-fish processing including viscera, skin, scales, bones, and skeletons are becoming a major problem for industries, causing environmental pollution and the loss of large quantities of high-value nutrients such as omega 3, 6, and 9 unsaturated fatty acids.
Our studies [2] show that the by-product of Basa-fish processing is $59 \%$. Thus, there will be about $65-70$ thousand tons of waste each year. Of which, $8.4 \%$ are fatty acids, equivalent to $546.000-588.000$ tons. Omega 3, 6, and 9 fatty acids of by-product are 57\%, meaning that 300.000-335.000 tons of omega 3,6 , and 9 annually are not used properly for its role.

Omega 3, 6, and 9 play an important role and is necessary for the human body. The body cannot self synthesis these omegas which can prevent cardiovascular diseases, cancer, lower blood pressure, lower cholesterol, and triglycerides in blood, brain accretion, and cardiac regulation and prevent thrombosis $[3,4]$.

The production process of omega 3,6, and 9 has been done by many methods as distillation in high temperature to give the useful compounds [5], crystalline at low temperature in ethanol, acetone or solvent mixtures [6], the supercritical fluid used as carbon dioxide $\left(\mathrm{CO}_{2}\right)$ at $31.1^{\circ} \mathrm{C}$ and $72.9 \mathrm{~atm}$ to achieve the all of fatty acids [7, 8]. Silver-coated chromatography and high-performance chromatography methods 
may isolate polyunsaturated fatty acids [9-11], using the complex of urea is the method to concentrate polyunsaturated fatty acids from waste of poultry and fish [12-15].

Deep eutectic solvents (DESs) are now widely acknowledged as a new class of ionic liquid analogues due to their characteristics and properties that are similar to ionic liquids. DESs show great promise as green solvents because they have the important properties such as biodegradability, low toxicity, and easy preparation [16]. DES was successfully used to efficiently extract baicalin from Scutellaria baicalensis Georgi by Wang et al. [17]. In this work, we introduce some initial results when using DES to separate and enrich omega 3, 6, and 9 in the fat of Vietnam's Basa fish processing waste.

\section{Materials and Methods}

2.1. Materials. The ionic liquid-DES is synthesized from the choline chloride and urea that were supported by Acros Organics Company.

A volume $1750 \mathrm{~g}$ of Basa fish was processed according to the exporting fish processing method. The average percentages of the fat, fillet meat, and by-products are shown in Table 1 . In which, the by-product was dominant $(58.8 \%)$ and was used to separate and enrich the omega 3, 6, and 9.

\subsection{Synthesis of the Ionic Liquid-DES}

2.2.1. Sample Preparation. The general procedure to synthesize ionic liquid-DES based on choline chloride and urea $[18,19]$ as follows: choline chloride and urea are mixed together at a molar ratio of $1: 1$ (and 2:1) in a flask fitted with a heating element and magnetic stirrer. The mixture was heated to $60^{\circ} \mathrm{C}$ for 5 to 7 minutes until it becomes homogeneous. Cooling at room temperature to prevent the crystallization occurs. When changing the molar ratio between choline chloride and urea to $1: 2$ and performing the same as described above, then cooling the reaction mixture down to room temperature, the mixture rapidly crystallizes into solids.

2.2.2. DES's Characteristics. The used analysis methods include FTIR on EQUINOX 55 (Bruker), frequency from 400 to $4000 \mathrm{~cm}^{-1}, \mathrm{KBr}$ template, the NMR technology by Brucker AC 500, and TGA-DSC by LABSYS evo SETARAM equipments. Viscosity is determined by DV III Ultra (Brookfield). Water concentration is determined by SCHOTT Instruments TitroLine KF trace.

\subsection{Omega 3, 6, and 9 Separation and Enrichment}

2.3.1. Sample Preparation. The by-product was added with 2 liters of water and boiled for 30 minutes. The mixture was allowed to cool down to $4^{\circ} \mathrm{C}$. The mixture was separated into two parts after cooling. The above part is a white grease layer that was separated and weighed $86.10 \mathrm{~g}$. The rest was filtered, dried at $45-50^{\circ} \mathrm{C}$ in vacuum, and weighed $942.80 \mathrm{~g}$. The fatty acid was extracted from both above parts by methanol and $\mathrm{n}$-hexane. In $86.6 \mathrm{~g}$ of the grease, the obtained result was $75.175 \mathrm{~g}$ of fatty acid, corresponding to a yield of $87.3 \%$. In
Table 1: Parts of catfish details.

\begin{tabular}{lccc}
\hline No. & Products & Weight $(\mathrm{g})$ & Percentage $(\%)$ \\
\hline 1 & Fat & 106.01 & 6.057 \\
2 & Fillet meat & 615.00 & 35.142 \\
3 & By-products & 1028.99 & 58.800 \\
4 & Error & & 0.001 \\
\hline
\end{tabular}

$942.80 \mathrm{~g}$ of the extracted solution, the fatty acid was not found; i.e., there was not fatty acid in this section.

The obtained fatty acids were esterified by methanol with an FA:methanol ratio of $10: 1$. The mixture was heated to $60^{\circ} \mathrm{C}$ and stirred at $120 \mathrm{rpm}$ for 3 hours. Next, the mixture was cooled down to room temperature. Then, the ester products were separated and washed several times. Finally, $\mathrm{Na}_{2} \mathrm{SO}_{4}$ was used to remove water from the methyl ester of FA. The final products were labeled "methyl esters." The chemical compositions of methyl esters were analyzed by the GC-FID method.

2.3.2. Omega 3, 6, and 9 Separation and Enrichments from Methyl Esters by DES. Methyl ester, methanol, and DES with a ratio of $20(\mathrm{~g}): 200(\mathrm{~g}): \mathrm{m}(\mathrm{g})$ were added to a 3-stage vial equipped with a backwash, heating element, and stirrer at $120 \mathrm{rpm}$ and heated in a temperature of $45^{\circ} \mathrm{C}$ for 1 hour. The obtained homogeneous mixture was allowed to cool down to $4^{\circ} \mathrm{C}$ and then cooled at $4^{\circ} \mathrm{C}$ for 8 hours. The resulting mixture was divided into two layers: the upper layer was liquid and the bottom layer was the crystal solid. The crystal part was washed with cold methanol. The washed methanol was added into the liquid part above, then was evaporated methanol in a vacuum evaporator, dried by $\mathrm{Na}_{2} \mathrm{SO}_{4}$, and analyzed the chemical compositions.

The crystal solid was added with $200 \mathrm{ml} \mathrm{H}_{2} \mathrm{O}$, boiled, and stirred until they dissolved and formed two layers. The upper layer contained the fatty acids. These FAs were separated and then removed water by $\mathrm{Na}_{2} \mathrm{SO}_{4}$. Finally, the obtained fatty acids were analyzed for the chemical compositions by GC/FID method. The lower layer contained methanol, water, and DES. The methanol and water were removed by the evaporation in vacuum. DES rechecked the physical properties for reusable purpose. In this work, the mass of DES has been changed from $5 \mathrm{~g}$ to $10,15,20,25$, and $30 \mathrm{~g}$.

2.4. Determination of Fatty Acids. The fatty acids were obtained from the by-products, and the unsaturated fatty acids by DES were analyzed by GC-FID method (GC-Agilent $6890 \mathrm{~N}$, flame ionization detector (FID), HP-INOWAX GC column: $30 \mathrm{~m} \times 0.25 \mathrm{~mm} \times 0.25 \mu \mathrm{m}$, the temperature range of $159-245^{\circ} \mathrm{C}$; nitrogen).

\section{Results and Discussion}

\subsection{Synthesis Ionic Liquid-DES}

3.2.1. Synthesis DES Base on Choline Chloride and Urea. Both choline chloride and urea are soluble in water. The melting points of choline chloride and urea were at $302^{\circ} \mathrm{C}$ and $133^{\circ} \mathrm{C}$, respectively. However, their mixture becomes a homogeneous solution as increasing the temperature to 
$60-75^{\circ} \mathrm{C}$. The products of reaction depend on the mass ratio of choline chloride and urea. Moreover, some by-products such as ammonium cyanide, $\mathrm{NH}_{3}, \mathrm{HOCN}$, and biurea can be formed at reaction temperature, as below:

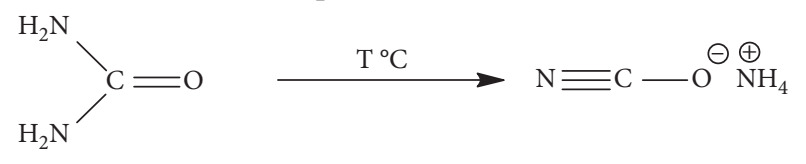

Ammonium cyanide is destroyed, and $\mathrm{NH}_{3}$ will be formed as follows:

$\mathrm{N} \equiv \mathrm{C}-\mathrm{O} \stackrel{\ominus}{\stackrel{\oplus}{\mathrm{NH}}}$ $\mathrm{N} \equiv \mathrm{C}-\mathrm{OH}+\mathrm{NH}_{3}$

(2)
In addition, two urea molecules can combine to form biurea [20]:
2<smiles>NC(=O)NC(=O)NC([NH2+])=O</smiles>

Therefore, the reaction temperature and mass ratios of choline chloride and urea must be selected to prevent the formation of by-product.

(1) Choline Chloride: Urea (1:1) Solution.

$$
\begin{aligned}
& {\left[\mathrm{CH}_{3}-\underset{\mathrm{CH}_{3}}{\stackrel{\mathrm{CH}_{3}}{\mathrm{CH}_{3}}} \mathrm{CH}_{2}-\mathrm{CH}_{2}-\mathrm{OH}\right] \mathrm{Cl} \stackrel{\ominus}{\stackrel{\left.+\mathrm{CO}\left(\mathrm{NH}_{2}\right)_{2}\right]}{\longrightarrow}}\left[\mathrm{CH}_{3}-\stackrel{\mathrm{CH}_{3}}{\left.\right|_{\mathrm{CH}_{3}} ^{\oplus}} \mathrm{CH}=\mathrm{CH}_{2}\right] \Theta-\mathrm{O} \equiv \mathrm{C}} \\
& +\mathrm{NH}_{4} \mathrm{Cl}+\mathrm{H}_{2} \mathrm{O}
\end{aligned}
$$

(2) Choline Chloride: Urea (2:1) Solution.
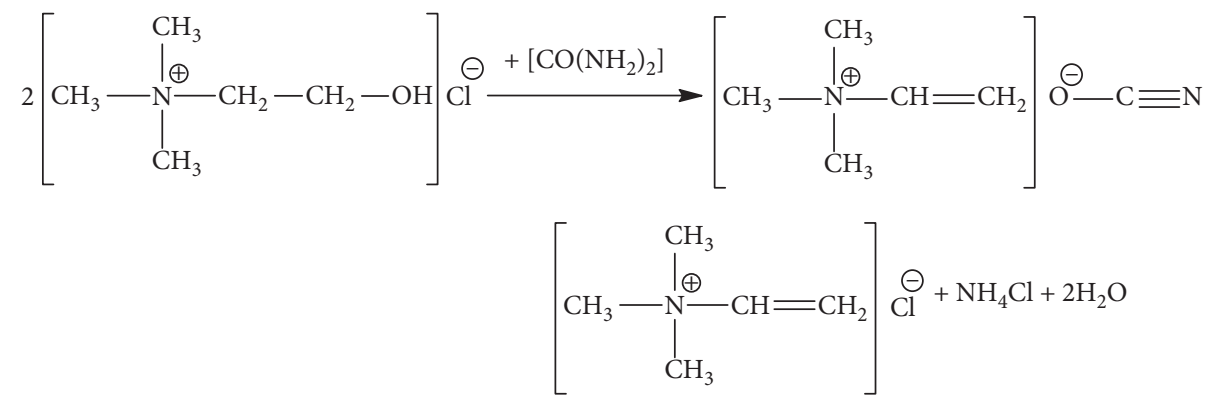

By-products in both cases are water, ammonium chloride, and ammonium hydroxide. These can be removed by heating in vacuum at low temperature $\left(<60^{\circ} \mathrm{C}\right)$. Anionic $\mathrm{NCO}^{-}$and cation choline combine by weak static bond, so this mix will melt at low temperature and does not crystallize at room temperature $\left(32-33^{\circ} \mathrm{C}\right)$.

(3) Choline Chloride: Urea (1:2) Solution.

$$
\begin{aligned}
& {\left[\mathrm{CH}_{3}-\underset{\mathrm{CH}_{3}}{\stackrel{\mathrm{CH}_{3}}{\mathrm{~N}}} \mathrm{CH}_{2}-\mathrm{CH}_{2}-\mathrm{OH}\right] \mathrm{Cl} \stackrel{\ominus}{\stackrel{\left.+\mathrm{CO}\left(\mathrm{NH}_{2}\right)_{2}\right]}{\longrightarrow}}\left[\mathrm{CH}_{3}-\stackrel{\mathrm{CH}_{3}}{\stackrel{\mathrm{CH}^{-}}{\mathrm{CH}_{3}} \mathrm{CH}}=\mathrm{CH}_{2}\right] \mathrm{O}-\mathrm{C} \equiv \mathrm{N}} \\
& +\mathrm{HO}-\mathrm{C} \equiv \mathrm{N}+\mathrm{NH}_{4} \mathrm{Cl}+\mathrm{NH}_{4} \mathrm{OH}
\end{aligned}
$$


TABLE 2: Physical index of DES solution at $30^{\circ} \mathrm{C}$.

\begin{tabular}{lccc}
\hline No. & Index & \multicolumn{2}{c}{ Choline chloride : urea ratio } \\
& & $1: 1$ ratio & $2: 1$ ratio \\
\hline 1 & $\mathrm{pH}$ & 6.65 & 5.92 \\
2 & Density $(\mathrm{g} / \mathrm{ml})$ & 1.197 & 1.167 \\
3 & Viscosity $(\mathrm{cP})$ & 61.5 & 57.3 \\
4 & Electronic conductivity $(\mathrm{mS})$ & 1.64 & 2.69 \\
5 & Water concentration $(\%)$ & 0.65 & 0.81 \\
\hline
\end{tabular}

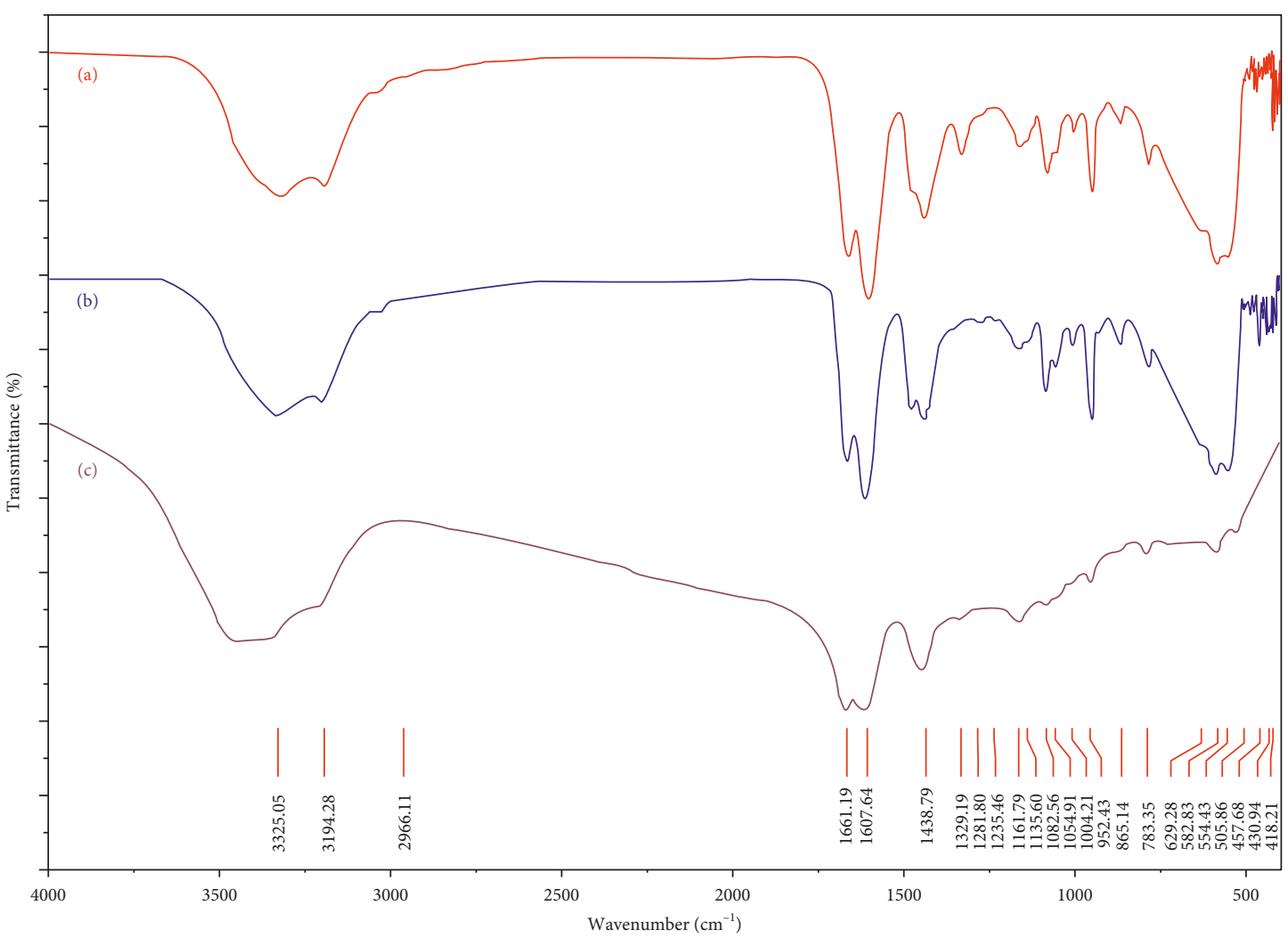

FIGURE 1: FTIR of DES solutions were synthesized with the choline chloride/urea molar ratios: a-(1:1), b-(2:1), c-(1:2).

With $1: 2$ ratio of choline chloride : urea, the by-products include by-products in case of $1: 1$ ratio and isocyanic acid. This is the factor which changes products' comeback initial state and crystallize at room temperature.

Based on this initial survey, we choose DES solution with $1: 1$ and $2: 1$ ratio of choline chloride: urea to continue optimization to determine the best ratio.

3.2.2. Physical Properties of DES Solution. Physical properties of DES solution with choline chloride : urea ratio in 1 : 1 and $2: 1$ are shown in Table 2 .

Electronic conductivity of urea in water is $0.01 \mathrm{mS}$, while electronic conductivity of choline chloride in water is $5.6 \mathrm{mS}$. After the reaction, electronic conductivity of solution decreases clearly. In case of $2: 1$ ratio, the higher value of electronic conductivity can be explained by the remaining quality of choline chloride after reaction. This result contributes in confirming the bond of choline chloride and urea as diagram (1) and to form new product with different electronic conductivities. The conductivity of urea in water is $0.01 \mathrm{mS}$, while the conductivity of choline chloride in water is $5.6 \mathrm{mS}$. When creating new products, the conductivity decreases considerably, where a 2:1 solution has a greater electrical conductivity, it is explained by the excess choline chloride content, which results in higher conductivity of the solution. This result confirms that choline chloride is chemically related to urea according to the reaction scheme (1) and produces a new product with conductivity different from that of the original.

\subsubsection{Analysis and Identification}

(1) FTIR Analysis. Figure 1 shows the FTIR spectra of DES solutions that were synthesized with the molar ratio of choline chloride/urea: a-(1:1), b-(2:1), c-(1:2). In FTIR of solutions (a) and (b), vibrational frequencies at $3230-3550 \mathrm{~cm}^{-1}$ and $3445.63 \mathrm{~cm}^{-1}$ can be attributed to the 


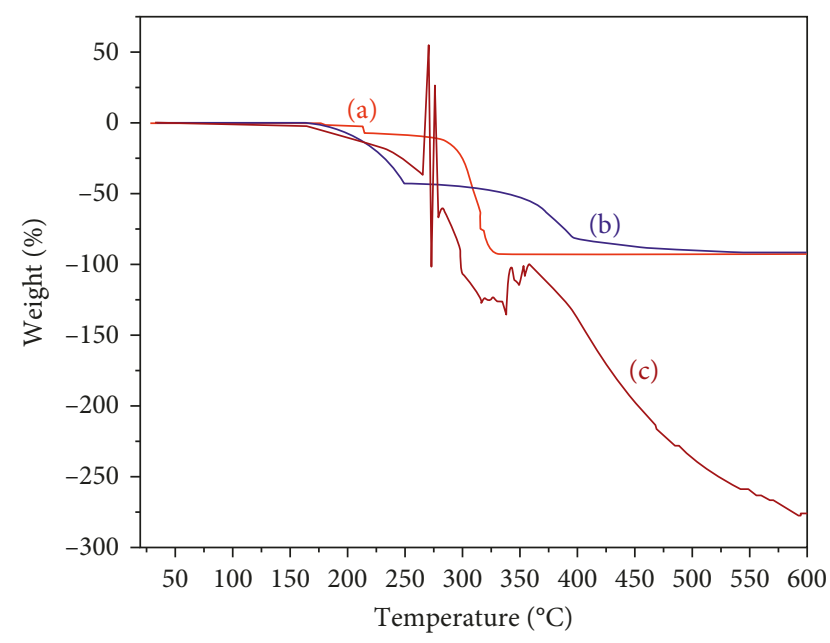

FIgUre 2: TGA of (a) choline chloride, (b) urea, and (c) choline chloride: urea $1: 1$.

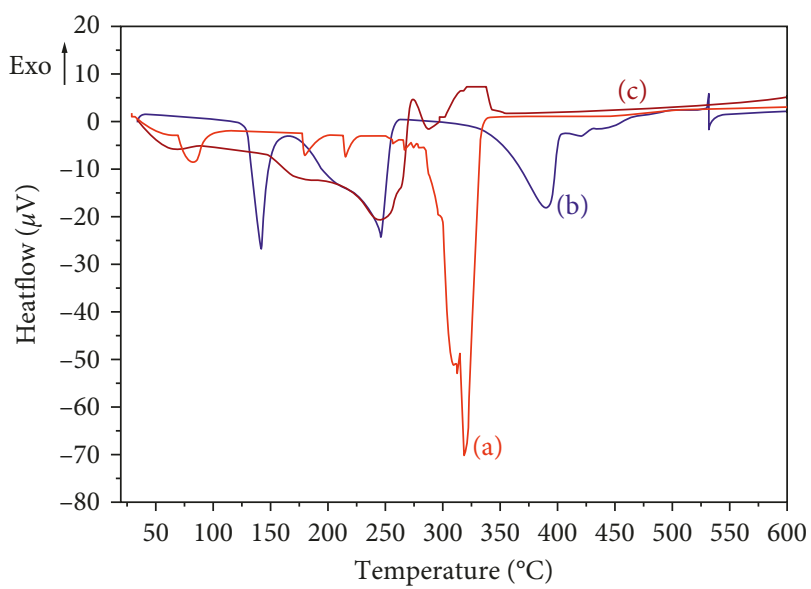

FIGURE 3: DSC of (a) choline chloride, (b) urea, and (c) choline chloride : urea $(1: 1)$.

vibration of the hydrogen bond between $\mathrm{OH}$ groups with average intensity. The vibrational frequencies at $3180-3220 \mathrm{~cm}^{-1}$ and $3194.28 \mathrm{~cm}^{-1}$ are the frequencies of $\mathrm{N}-\mathrm{H}$ in the amide group of urea. The vibrational frequencies at $1660-1705 \mathrm{~cm}^{-1}$ and $1661.19 \mathrm{~cm}^{-1}$ are the frequencies of $\mathrm{C}=\mathrm{O}$ in urea. And the frequencies of $1590-1620 \mathrm{~cm}^{-1}$ and $1607.64 \mathrm{~cm}^{-1}$ indicate the average vibration of $\mathrm{N}-\mathrm{H}$ in the amide group that combines with vibration of $\mathrm{C}-\mathrm{N}$ in urea.

In $2800-3300 \mathrm{~cm}^{-1}$, the longer vibration of $\mathrm{N}-\mathrm{H}$ bond in amide of urea and $\mathrm{O}-\mathrm{H}$ shows that the amide group of urea bond to $\mathrm{O}-\mathrm{H}$ of choline. The range from 2700 to $3000 \mathrm{~cm}^{-1}$ and 2966.11 indicates the strong vibration of $-\mathrm{NH}_{2}$. The range from 2280 to $3380 \mathrm{~cm}^{-1}$ is the average vibration of $\mathrm{N}-\mathrm{H}$ bond in $-\mathrm{NH}_{3}{ }^{+}$.

Especially, in the range of $2100-2225 \mathrm{~cm}^{-1}, 2158.95 \mathrm{~cm}^{-1}$ contributes to vibration of $\mathrm{N} \equiv \mathrm{C}^{-} \mathrm{O}^{-}$(cyanide ionic). Vibration at $629.28 \mathrm{~cm}^{-1}$ is also the strong vibration of $\mathrm{NCO}^{-}$. In $1150-1210 \mathrm{~cm}^{-1}, 1161.79 \mathrm{~cm}^{-1}, \mathrm{C}-\mathrm{N}$ bond vibrates with average intensity. The $1135.60 \mathrm{~cm}^{-1}, 1082.56 \mathrm{~cm}^{-1}$, and

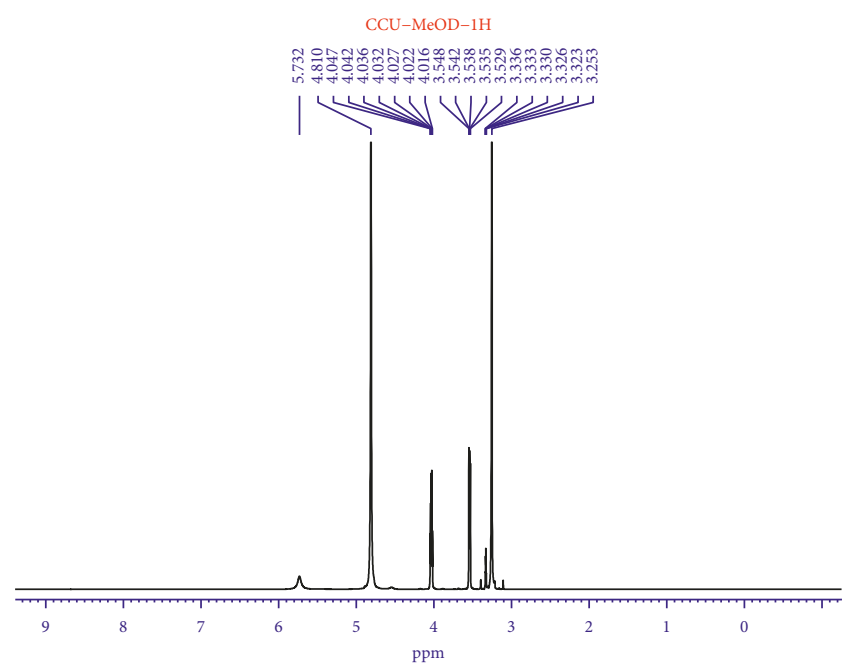

(a)

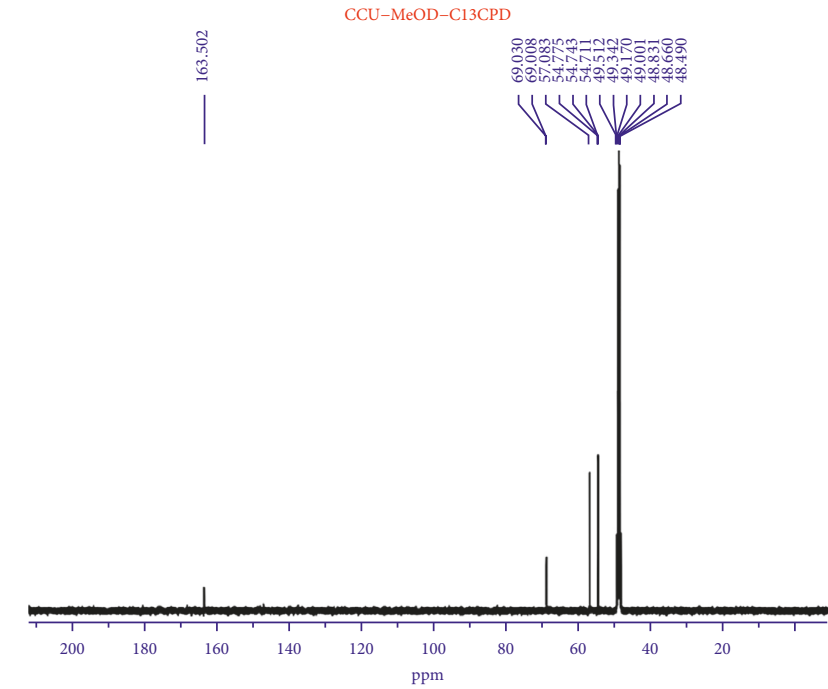

(b)

Figure 4: NMR spectrum of DES $(1: 1):{ }^{1} \mathrm{H}$ NMR (a) and ${ }^{13} \mathrm{C}$ NMR (b).

$1054.91 \mathrm{~cm}^{-1}$ positions are the little strong vibration of C-N in choline chloride.

The FTIR spectra of solutions show unclearly because of the crystallization. Results of chemical-physical properties and FTIR show that both solutions are the good ionic liquids.

(2) TGA and DSC Analysis of DES (1:1). The clear difference between thermal gravity of choline chloride, urea, and product mixes is displayed in Figure 2. In $350-400^{\circ} \mathrm{C}$ range, choline chloride (a) and urea (b) are both completely decomposed. But in their mix, at $250^{\circ} \mathrm{C}$, there is fast changing mass including increasing and decreasing mass. After that, their mix's mass decreased slowly to $80^{\circ} \mathrm{C}$. This demonstrates that between choline chloride and urea, there is bonding, not to mechanical mixing.

Similar to TGA analysis, DSC result of choline chloride, urea, and their products is also clearly different (Figure 3). 
FID1 B, back signal (C:IVN01PCC00060\2016\04|Fatty acid\06\06-04-2016 2016-04-06 22-25-01\16040571.D)

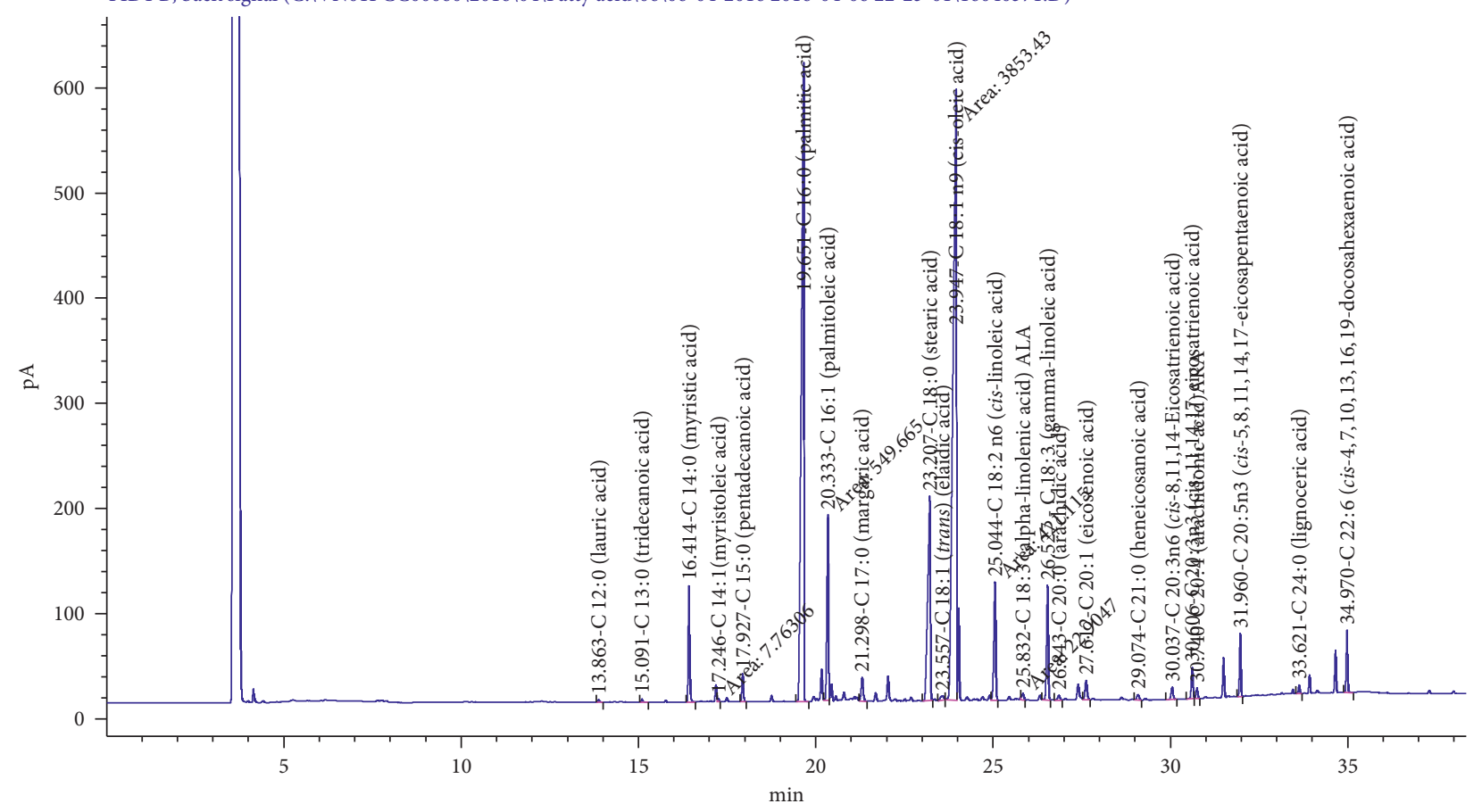

(a)

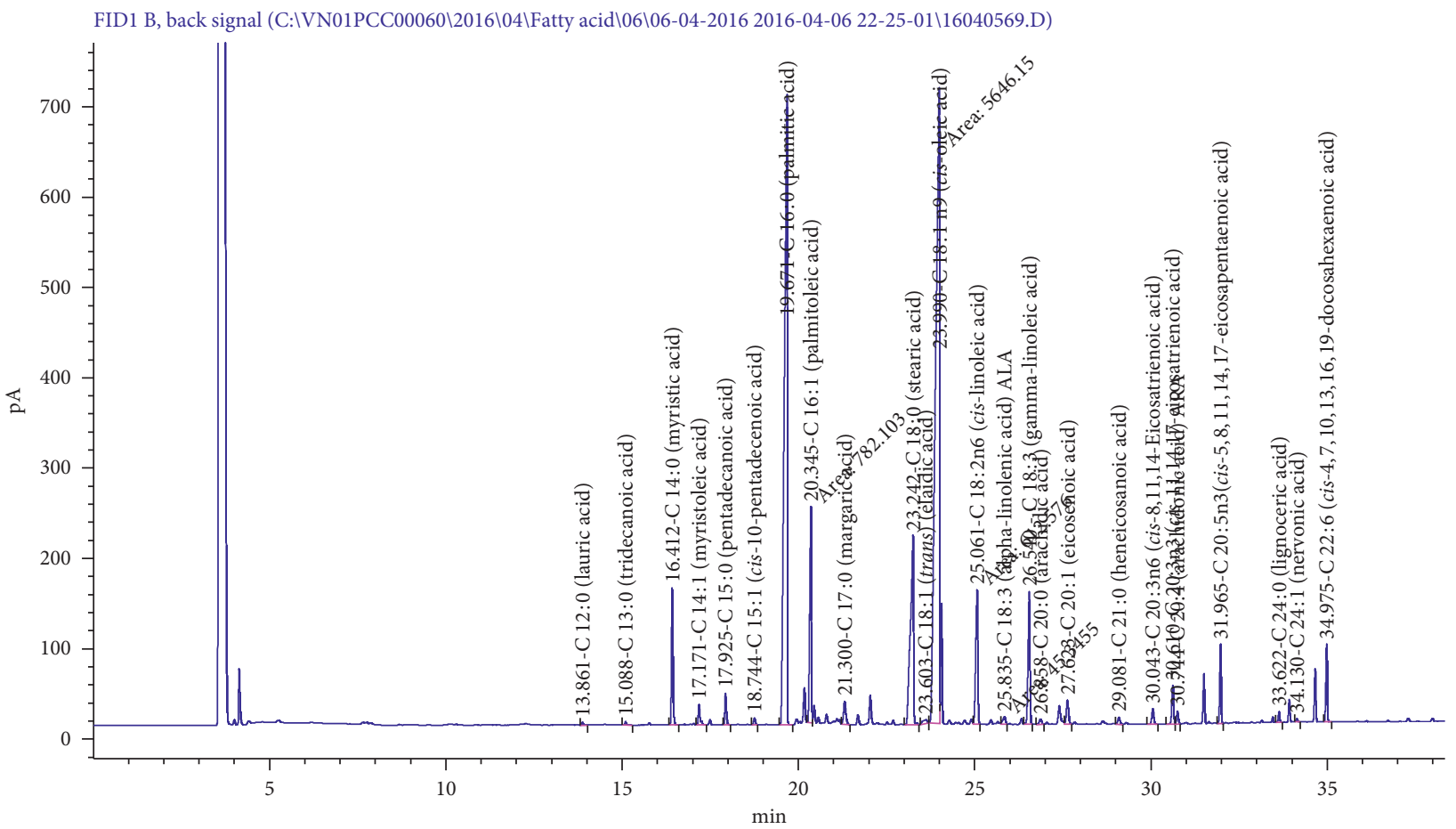

(b)

FIgURe 5: Chromatogram of GC/FID analysis of the fatty acids in methyl ester (a) and in methyl ester-DES (b).

Mix's crystallization temperature is about $300^{\circ} \mathrm{C}$, while choline chloride crystallizes at $200^{\circ} \mathrm{C}$ and urea crystallizes at 100,250 , and $400^{\circ} \mathrm{C}$.

(3) NMR Analysis of DES (1:1). Figure 4 shows the NMR spectrum of DES solution that was synthesized with the molar ratio of choline chloride/urea: $(1: 1)$. Results are shown as follows: (a) ${ }^{1} \mathrm{H} \mathrm{NMR}\left(\mathrm{CDCl}_{3}, 500 \mathrm{MHz}\right): 3.2(1 \mathrm{H})$, $3.3(5 \mathrm{H}), 3.5(5 \mathrm{H}), 5.4(7 \mathrm{H}), 5.8(1 \mathrm{H}), 5.7(1 \mathrm{H})$ and $(\mathrm{b}){ }^{13} \mathrm{C}$ $\operatorname{NMR}\left(\mathrm{CDCl}_{3}, 125 \mathrm{MHz}\right): 58.1,59.5,63.0,63.0,118$, and 163.5 .

3.2. Determination of Fatty Acid in Samples. The composition of the crude materials was determined by GC/FID method (Figure 5(a)) and is shown in Table 3. 
TABLE 3: The chemical compositions of fatty acids before separation and enrichment by DES.

\begin{tabular}{lccc}
\hline No. & Fatty acids & Raw methanol extract (\%) & Methyl ester (\%) \\
\hline 1 & Saturated fatty acids & 31.37 & 35.58 \\
2 & Unsaturated fatty acid & 2.85 & 3.35 \\
3 & Omega 3 & 2.00 & 1.84 \\
4 & Omega 6 & 16.44 & 14.48 \\
5 & Omega 9 & 40.71 & 40.63 \\
6 & Undefined & 6.63 & 4.12 \\
Total & & 100.00 & 100.00 \\
\hline
\end{tabular}

TABLE 4: Classification of saturated fatty acids, unsaturated fatty acids, and omega in methyl ester.

\begin{tabular}{|c|c|c|}
\hline Classification & Name of compounds & Percentage (\%) \\
\hline \multirow{4}{*}{ SFA } & Myristic acid (C14:0) & 1.96 \\
\hline & Palmitic acid (C16:0) & 26.55 \\
\hline & Stearic acid $(\mathrm{C} 18: 0)$ & 6.78 \\
\hline & Arachidic acid $(\mathrm{C} 20: 0)$ & 0.29 \\
\hline USFA & Palmitoleic acid (C16:1) & 3.35 \\
\hline \multirow{4}{*}{ OM-3 } & $\begin{array}{c}\text { cis-5,8,11,14,17-Eicosapentaenoic acid (C20:5n3) } \\
\text { (EPA) }\end{array}$ & 0.42 \\
\hline & $\alpha$-Linolenic acid $(\mathrm{C} 18: 3 \mathrm{n} 3)(\mathrm{ALA})$ & 0.46 \\
\hline & cis-11,14,17-Eicosatrienoic acid (C20:3n3) & 0.15 \\
\hline & $\begin{array}{l}\text { Nervonic acid (C24:1n9) + cis-4,7,10,13,16,19- } \\
\text { docosahexaenoic acid (C22:6n3) (DHA) }\end{array}$ & 0.63 \\
\hline \multirow{4}{*}{ OM-6 } & Linoleic acid (C18:2n6c) (LA) & 12.41 \\
\hline & $\gamma$-Linolenic acid (C18:3n6) (GLA) & 1.05 \\
\hline & cis-8,11,14-Eicosatrienoic acid (C20:3n6) & 0.18 \\
\hline & Arachidonic acid (C20:4n6) (AA) & 0.48 \\
\hline \multirow{2}{*}{ OM-9 } & Oleic acid $(\mathrm{C} 18: \ln 9 \mathrm{c})$ & 40.21 \\
\hline & cis-11-Eicosenoic acid $(\mathrm{C} 20: \ln 9)$ & 0.42 \\
\hline Undefined & & 4.11 \\
\hline Total & & 100.00 \\
\hline
\end{tabular}

The chemical compositions of methyl esters were not significantly different to one's before esterification reaction. The total content of omega 3,6, and 9 in the raw materials is $57 \%$; $39 \%$ are non-omega 3, 6, and 9 fatty acids; $4 \%$ are unidentified substances. Omega 3, 6, and 9 and non-omega are identified in Table 4 and Figure 5(a).

3.3. Separation and Enrichment of Omega 3, 6, and 9 by DES. In this work, we use DES with a choline chloride/urea ratio of $1: 1$ to separate and enrich omega 3,6 , and 9 because it has a $\mathrm{pH}$ of nearly 7 , small electronic conductivity (1.64), and water low content $(0.65 \%)$. These properties will not cause side effects with multiple coupling compounds in the sample. Figure 6 illustrates the process of enriching omega from the sample.

Effectiveness of process delamination during the participation of DES is shown in Table 5.

The performance of omega FA separation from the liquid layer varies from $12 \%$ to $19.5 \%$, depending on the mass of DES (5-30 g per $20 \mathrm{~g}$ of methyl ester). It changes insignificantly when increasing the mass of DES. For omega 3,6 , and 9 , the separation efficiency is between $17 \%$ and $29 \%$, depending on the mass of DES. This performance can reach over $50 \%$ for omega 3 and 6 as shown in Table 6 .
The omega fatty acid compositions were determined by the GC/FID method (Figure 5(b)) and are shown in Table 7 and Figure 7. It is that although the separation efficiency is low, the purity of omega 3,6 , and 9 was high. The content of omega FA was reached from $83 \%$ to $91 \%$ for the first separation, and the optimal mass of DES was in a range from 15 to $20 \mathrm{~g} / 20 \mathrm{~g}$ of methyl esters (Table 7 and Figure $7(\mathrm{a})$ ).

Eighty percent FA of methyl esters is combined with DES to form the crystal solid, as shown in Section 2.3. In this mixture, there are mainly SFA and UFA. Omega FAs were accounted for only $20-30 \%$ as shown in Table 8 and Figure 7(b).

The FA separation process from the crystal solid was also carried out with DES; however, the omega fatty acids were not obtained. This result indicated that DES was not capable of separating omega FA from the non-omega FA when the omega FA/non-omega FA ratio was less than 1 .

\section{Conclusions}

The ionic liquid-deep eutectic solvent was successfully synthesized with the molar ratio of choline chloride/urea of $1: 1$ and $2: 1$. The characteristics of DES were determined and demonstrated by FTIR, TGA, DSC, ${ }^{1} \mathrm{H}-\mathrm{NMR}$, and ${ }^{13} \mathrm{C}$ NMR analysis methods. DES's physical properties were 


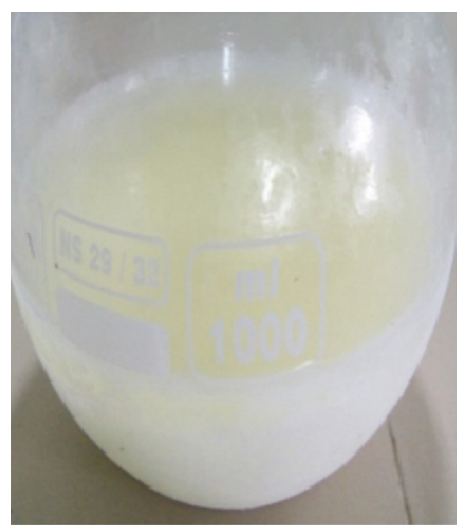

(a)

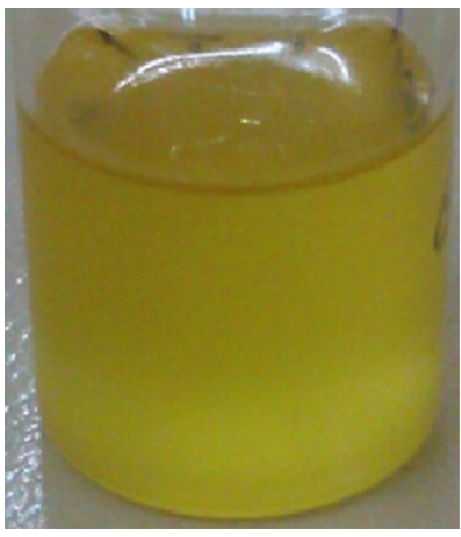

(d)

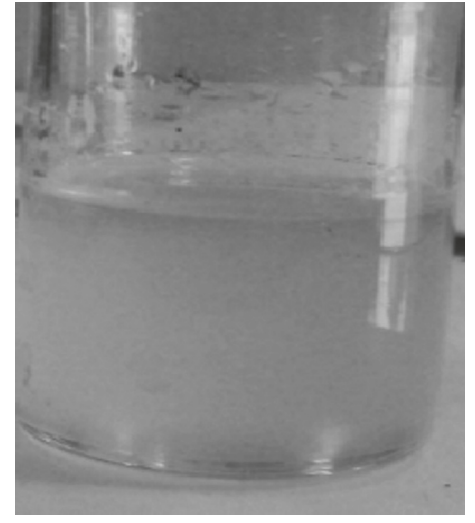

(b)

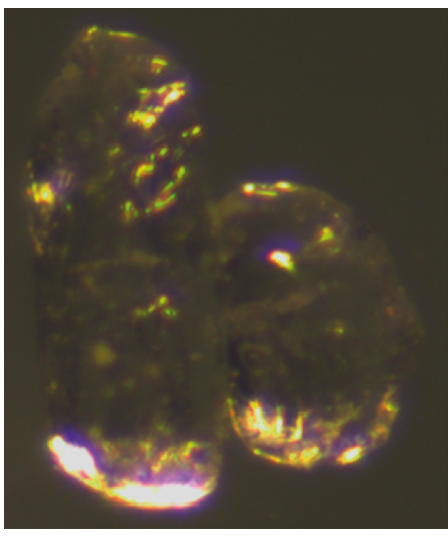

(e)

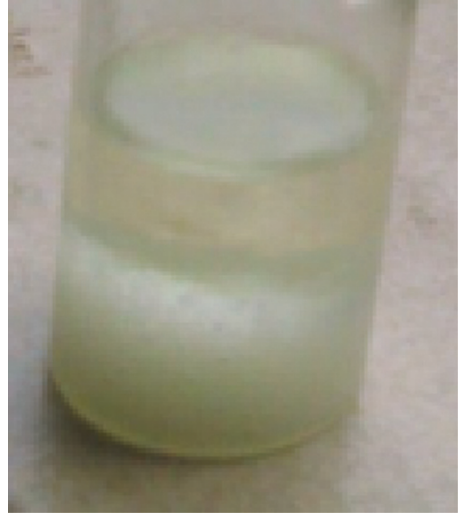

(c)

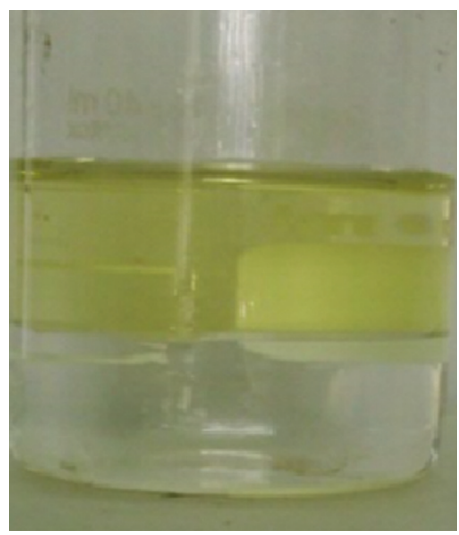

(f)

FIGURE 6: (a) DES and methanol extract; (b) DES, methanol extract, and methyl ester after stirring and heating; (c) mixture after 8 hours of cooling; (d) omega-rich fatty acids in the liquid layer; (e) crystal solid under the microscope; (f) fatty acids separated from crystal solid.

TABLE 5: The dependence of the liquid/crystal solid ratios on mass of DES.

\begin{tabular}{lccc}
\hline Mass of DES $(\mathrm{g})$ & Liquid $(\mathrm{g})$ & Crystal solid $(\mathrm{g})$ & Loss $(\mathrm{g})$ \\
\hline 5 & 2.40 & 17.52 & 0.08 \\
10 & 2.87 & 17.08 & 0.05 \\
15 & 3.30 & 16.60 & 0.10 \\
20 & 3.60 & 16.33 & 0.07 \\
25 & 3.82 & 16.09 & 0.09 \\
30 & 3.90 & 16.00 & 0.10 \\
\hline
\end{tabular}

TABle 6: The efficiency of omega FA separation from the liquid layer.

\begin{tabular}{lcccccc}
\hline \multirow{2}{*}{ Mass of fatty acids } & \multicolumn{5}{c}{ Mass of DES (g)/20 g methyl ester } \\
& 0 & 5 & 10 & 15 & 20 & 25 \\
\hline Omega 3, 6, and 9 FA (g) & 11.39 & 1.99 & 2.42 & 3.00 & 3.25 & 3.30 \\
Efficiency (\%) & - & 17.47 & 21.06 & 26.33 & 28.53 & 28.97 \\
Omega 3 and 6 FA (g) & 3.26 & 1.12 & 0.89 & 1.22 & 1.74 & 1.21 \\
Efficiency (\%) & - & 34.00 & 27.30 & 37.42 & 53.37 & 37.12 \\
\hline
\end{tabular}

TABle 7: Fatty acid compositions of the liquid layer.

\begin{tabular}{|c|c|c|c|c|c|}
\hline Mass of DES (g) & SFA (\%) & UFA (\%) & Omega 3,6 , and $9(\%)$ & Undefined (\%) & Total (\%) \\
\hline 5 & 11.76 & 2.90 & 82.97 & 2.37 & 100 \\
\hline 10 & 7.46 & 3.14 & 84.35 & 5.05 & 100 \\
\hline 15 & 3.30 & 2.37 & 91.03 & 3.30 & 100 \\
\hline 20 & 2.99 & 2.64 & 90.30 & 4.34 & 100 \\
\hline 25 & 8.22 & 2.17 & 86.60 & 3.01 & 100 \\
\hline 30 & 6.66 & 3.70 & 85.52 & 4.12 & 100 \\
\hline
\end{tabular}




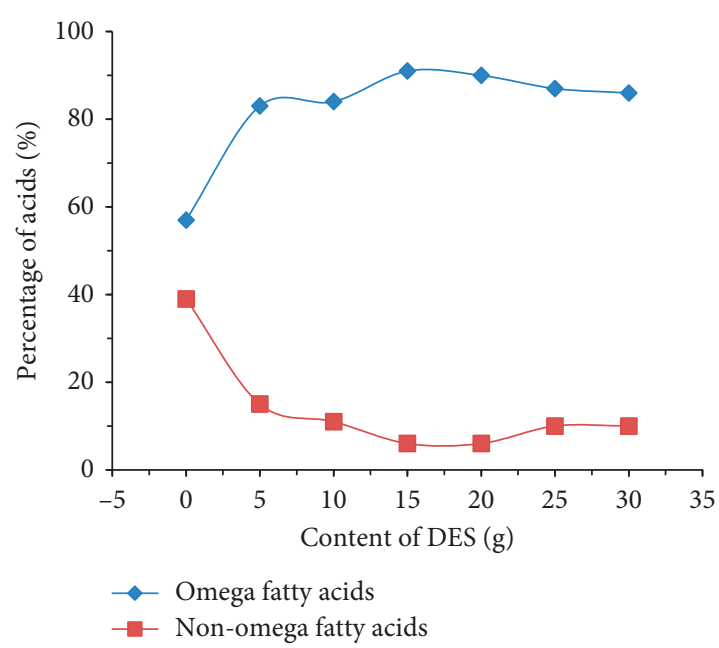

(a)

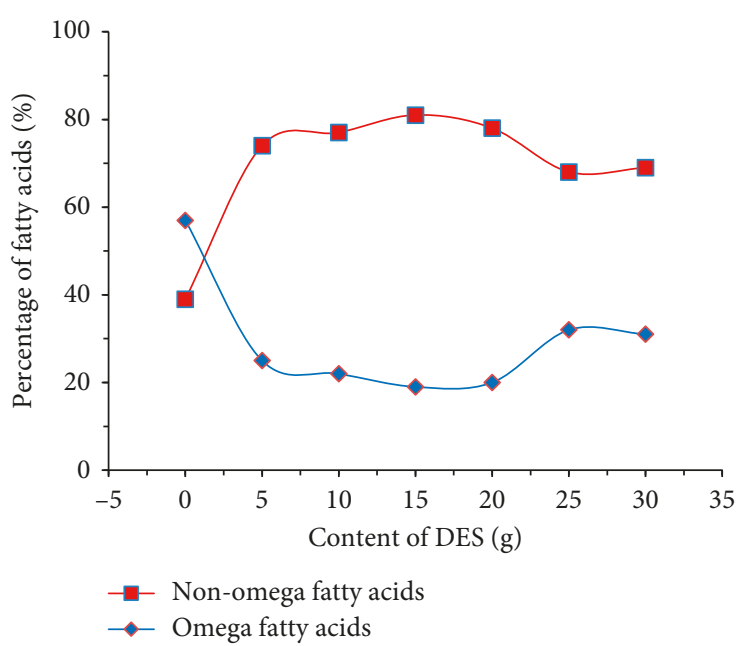

(b)

FIgURe 7: The dependence of omega FA and non-omega FA in the content of DES: (a) in liquid layer and (b) in crystal solid.

TABle 8: Fatty acid compositions of crystal solid.

\begin{tabular}{|c|c|c|c|c|c|}
\hline Mass of DES (g) & SFA (\%) & UFA (\%) & Omega 3,6 , and $9(\%)$ & Undefined (\%) & Total (\%) \\
\hline 5 & 60.45 & 13.80 & 25.32 & 0.43 & 100 \\
\hline 10 & 62.22 & 15.07 & 22.40 & 0.36 & 100 \\
\hline 15 & 65.73 & 15.12 & 18.57 & 0.58 & 100 \\
\hline 20 & 63.75 & 14.68 & 20.08 & 0.49 & 100 \\
\hline 25 & 55.43 & 12.41 & 31.64 & 0.52 & 100 \\
\hline 30 & 54.62 & 14.30 & 30.51 & 0.57 & 100 \\
\hline
\end{tabular}

determined: the electronic conductivity of DES is $1.64 \mathrm{mS}$ and $2.69 \mathrm{mS}$ and the viscosity is $61.5 \mathrm{cP}$ and $57.3 \mathrm{cP}$, corresponding to the molar ratio of choline chloride/urea of $1: 1$ and $2: 1$.

DES with a choline chloride/urea ratio of $1: 1$ was used to enrich omega 3, 6, and 9 because it has a $\mathrm{pH}$ of nearly 7 , small electronic conductivity (1.64), and water low content $(0.65 \%)$. The results show that the percentage of omega 3,6 , and 9 was increased from $57 \%$ in raw materials to $91 \%$ for the first separation. The optimal mass ratio is $20 \mathrm{~g}$ methyl acetate with $200 \mathrm{~g}$ methanol and 15-20 g DES.

DES was only used to separate and enrich the omega FA when the omega FA/non-omega FA ratio is greater than 1 .

\section{Data Availability}

The data used to support the findings of this study are available from the corresponding author upon request.

\section{Conflicts of Interest}

The authors declare that they have no conflicts of interest.

\section{Acknowledgments}

The authors wish to thank the Ministry of Education and Training of Vietnam, B2017.SPD.04 Project, for their financial support of this work.

\section{References}

[1] T. R. Roberts and C. Vidthayanon, "Systematic revision of the Asian catfish family Pangasiidae, with biological observations and descriptions of three new species," Proceedings of Academy of Natural Sciences of Philadelphia, vol. 143, pp. 97-144, 1991.

[2] T. X. Le Thi, "Survey composition and content of omega-3,6,9, extracted from catfish at Mekong delta Vietnam by extraction method with the traditional solvents," Vietnam Journal of Chemistry, vol. 55, no. 5e34, pp. 551-556, 2017.

[3] R. Kapoor and U. Patil, "Importance and production of omega-3 fatty acids from natural sources," International Food Research Journal, vol. 18, pp. 491-497, 2011.

[4] C. M. Yates, P. C. Calder, and G. Rainger, "Pharmacology and therapeutics of omega-3 polyunsaturated fatty acids in chronic inflammatorydisease," Pharmacology and Therapeutics, vol. 141, pp. 272-282, 2014.

[5] D. Patil and A. Nag, "Production of PUFA concentrates from poultry and fish processing waste," Journal of American Oil Chemists' Society, vol. 88, no. 4, pp. 589-593, 2011.

[6] L. Vázquez and C. C. Akoh, "Enrichment of stearidonic acid in modified soybean oil by low temperature crystallization," Food Chemistry, vol. 130, no. 1, pp. 147-155, 2012.

[7] F. Sahena, I. S. M. Zaidul, S. A. Jinap et al., "Fatty acid compositions of fish oil extracted from different parts of Indian mackerel (Rastrelliger kanagurta) using various techniques of supercritical $\mathrm{CO}_{2}$ extraction," Food Chemistry, vol. 120, no. 3, pp. 879-885, 2010.

[8] S. Tang, C. Qin, H. Wang et al., "Study on supercritical extraction of lipids and enrichment of DHA from oil-rich 
microalgae," Journal of Supercritical Fluids, vol. 57, no. 1, pp. 44-49, 2011.

[9] J. Guo, C. Wang, Z. Wu et al., "Purification of essential linoleic acid from pinus armandi franch seed oil by silver-silica gel chromatography column," in Proceedings of the 4th International Conference on Bioinformatics and Biomedical Engineering (ICBBE), vol. 1-4, Chengdu, China, June 2010.

[10] J. T. Dillon, J. C. Aponte, R. Tarozo, and Y. Huang, "Purification of omega-3 polyunsaturated fatty acids from fish oil using silver-thiolate chromatographic material and high performance liquid chromatography," Journal of Chromatography A, vol. 1312, pp. 18-25, 2013.

[11] P. Fagan and C. Wijesundera, "Rapid isolation of omega-3 long-chain polyunsaturated fatty acids using monolithic high performance liquid chromatography columns," Journal of Separation Science, vol. 36, no. 11, pp. 1743-1752, 2013.

[12] M. Wu, H. Ding, S. Wang, and S. Xu, "Optimizing conditions for the purification of linoleic acid from sunflower oil by urea complex fractionation," Journal of American Oil Chemists' Society, vol. 85, no. 7, pp. 677-684, 2008.

[13] L. Z. Cheong, Z. Guo, Z. Yang et al., "Extraction and enrichment of n-3 polyunsaturatedfatty acids and ethyl esters through reversible $\pi-\pi$ complexation with aromatic rings containing ionic liquids," Journal of Agricultural and Food Chemistry, vol. 59, no. 16, pp. 8961-896, 2011.

[14] V. Crexi, M. Monte, and L. A. Pinto, "Polyunsaturated fatty acid concentrates of carp oil: chemical hydrolysis and urea complexation," Journal of American Oil Chemists' Society, vol. 89, no. 2, pp. 329-334, 2012.

[15] C. Fie, J. Salimon, and M. Said, "Optimisation of urea complexation by Box-Behnken design," SainsMalays, vol. 39, pp. 795-803, 2010.

[16] E. L. Smith, A. P. Abbott, and K. S. Ryder, "Deep eutectic solvents (DESs) and their applications," Chemical Reviews, vol. 114, no. 21, pp. 11060-11082, 2014.

[17] H. Wang, X. Ma, Q. Cheng, X. Xi, and L. Zhang, "Deep eutectic solvent-based microwave-assisted extraction of baicalin from Scutellaria baicalensis Georgi," Journal of Chemistry, vol. 2018, Article ID 9579872, 10 pages, 2018.

[18] A. Florea, A. Petica, L. Anicai, and T. Visan, "Formation from choline chloride based ionic liquids," UPB Scientific Bulletin, Series B, vol. 72, no. 2, pp. 115-126, 2010.

[19] A. P. Abbott, S. Nandhra, S. Postlethwaite, E. L. Smith, and K. S. Ryder, "Electroless deposition of metallic silver from a choline chloride-based ionic liquid: a study using acoustic impedance spectroscopy, SEM and atomic force microscopy," Physical Chemistry Chemical Physics, vol. 9, no. 28, pp. 3735-3743, 2007.

[20] G. Wiedemann, "Biuret decomposition product of urea," Justus Liebig's Annalen der Chemie, vol. 68, no. 3, pp. 323-326, 2006. 

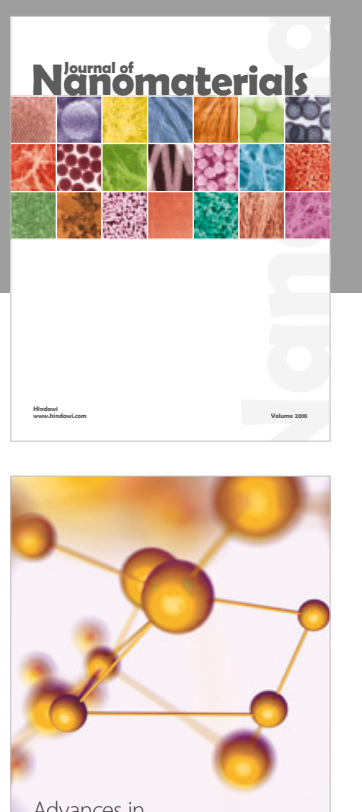

Physical Chemistry
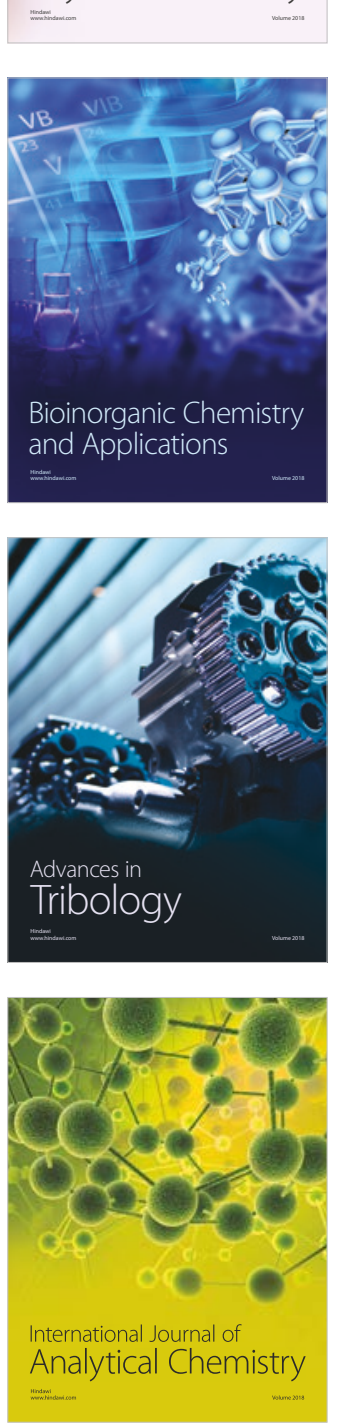

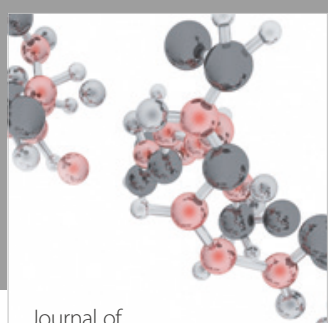

Analytical Methods

in Chemistry

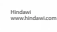

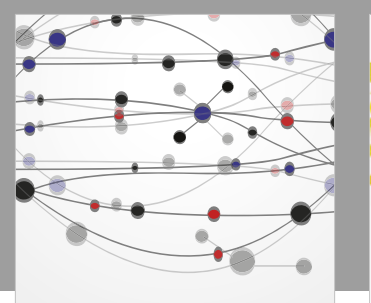

The Scientific World Journal

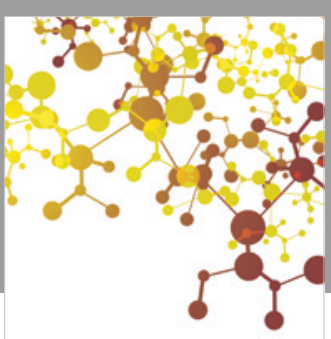

Journal of

Applied Chemistry
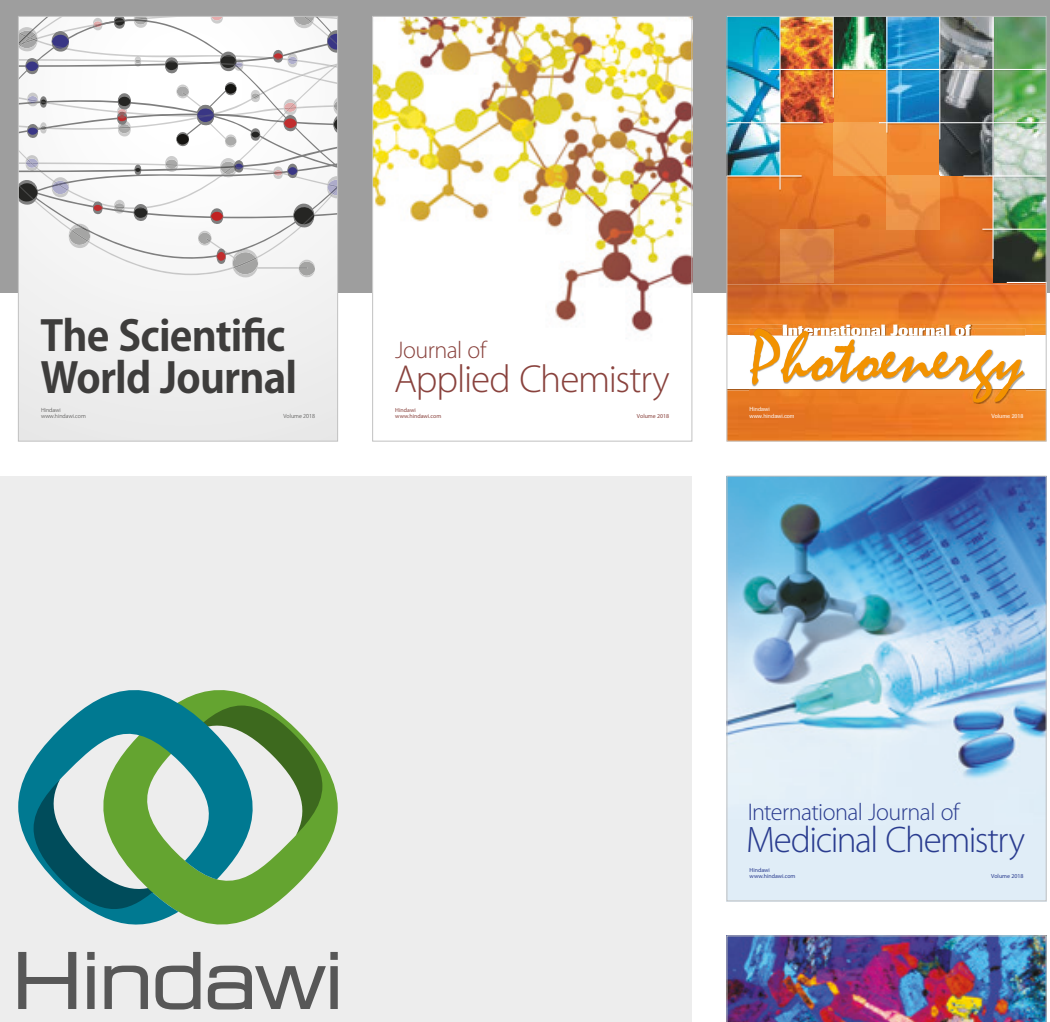

Submit your manuscripts at

www.hindawi.com
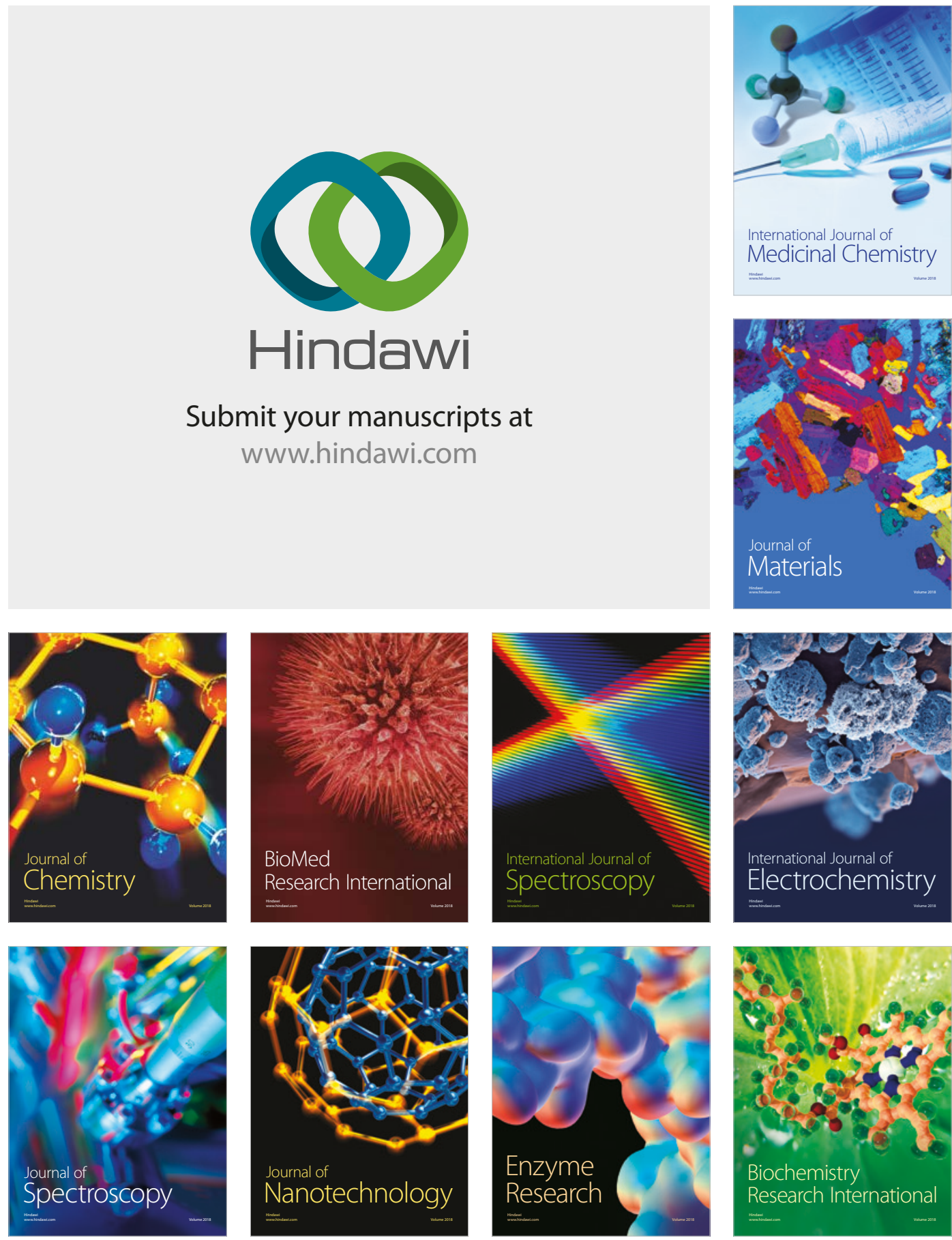
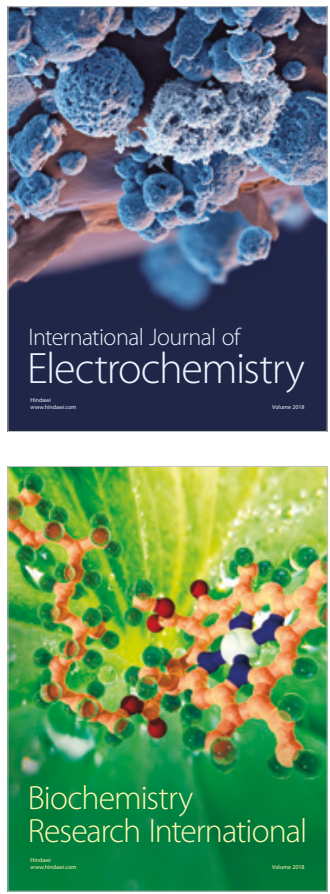